Revista Mexicana de Análisis de la Conducta - Mexican Journal of Behavior Analysis 2018 | Núm. 2 - diciembre | No. 2 • December | Vol. 44, 173-199

http://dx.doi.org/10.5514/rmac.v44.i2.68833

\title{
LEARNING AND RECIPROCITY IN COAL TITS PLAYING THE PRISONER'S DILEMMA GAME
}

\author{
APRENDIZAJE Y RECIPROCIDAD EN CARBONEROS \\ GARRAPINOS JUGANDO EL DILEMA DEL PRISIONERO
}

\author{
Luis M. Bautista and Beatriz Martín \\ Department of Evolutionary Ecology, National Museum of Natural \\ Sciences MNCN, Spanish Research Council CSIC
}

\begin{abstract}
Resumen
Los estudios del Dilema del Prisionero Iterado (DPI) en obtención del alimento muestran que los animales no cooperan, en contradicción con los modelos evolutivos que predicen que los animales cooperativos prevalecerán y se extenderán en las poblaciones. Esta contradicción podría deberse a una dificultad para aprender las reglas de DPI. Exploramos esta hipótesis con carboneros garrapinos, que en lugar de jugar entre ellos lo hicieron individualmente contra una computadora

Luis M. Bautista, Beatriz Martín, Department of Evolutionary Ecology, National Museum of Natural Sciences MNCN, Spanish Research Council CSIC. Current address of Beatríz Martín: Randbee, Calle Martínez Campos, 16, E 29001 Málaga, Spain.

This study was funded by project PB95-0102-CO2-01. LMB was supported by a postdoctoral contract from Spanish Ministry of Education and Science (MEC). We are grateful to L. Martínez and C. Mayo for their help conducting the experiments. Peerage of Science provided a noteworthy service to improve the manuscript. We thank the reviewing effort and kind comments of David Fisher, Klaus Jaffe, Michael Taborsky and Sabino Maggi.

Correspondence concerning the article should be addressed to: Luis M. Bautista, Department of Evolutionary Ecology, National Museum of Natural Sciences MNCN, Spanish Research Council CSIC. José Gutiérrez Abascal 2, 28006 Madrid, Spain (Email: lm.bautista@csic.es)
\end{abstract}


programada para entregar alimento aplicando la estrategia 'Toma y Daca' en una versión modificada del DPI, en la cual la típica matriz de pagos $\mathrm{T}>\mathrm{R}>\mathrm{P}>\mathrm{S}=0$ se relajó disminuyendo la tentación por defraudar y el castigo al ser defraudado según la relación $\mathrm{T}=\mathrm{R}>\mathrm{P}=\mathrm{S}>0$. Los carboneros garrapinos aumentaron la preferencia por defraudar un $10 \%$ durante el juego en comparación con una condición de referencia en la que el computador entregó la misma cantidad de alimento con una estrategia fija e independiente de las preferencias de las aves. Un análisis secuencial (ensayo por ensayo) demostró que las aves defraudaron regularmente y cooperaron al azar. Si bien la pequeña preferencia ( $10 \%)$ por defraudar observada en una versión del DPI relajada muestra que los experimentos del DPI podrían ser excesivamente estrictos para investigar la reciprocidad en animales, la ausencia de cooperación consigo mismos incluso en un DPI relajado sugiere que el diseño experimental utilizado en este trabajo es un buen punto de partida para explorar con otras especies los procesos de aprendizaje subyacentes a la cooperación.

Palabras clave: Dilema del prisionero iterado débil; toma y daca; juegos de forrajeo; Auto-reciprocidad; Periparus ater

\begin{abstract}
Foraging tests of the Iterated Prisoner's Dilemma (IPD) show animals defect, contrary to evolutionary models that predict cooperative animals will prevail and spread in populations. This contradiction could be due to IPD rules that could be too challenging to understand for most animals. We explored this hypothesis relaxing the payoff matrix of the IPD $(\mathrm{T}>\mathrm{R}>\mathrm{P}>\mathrm{S}=0)$ to a weak payoff-matrix $(\mathrm{T}=\mathrm{R}>\mathrm{P}=\mathrm{S}>0)$ and tested it with coal tits, which did not play one another; rather, each one played against a computer programmed to deliver food pellets according to the 'Tit for Tat' strategy. Despite the IPD was programmed with a weak payoff matrix, coal tits preferences to defect increased a $10 \%$ when playing the Game condition as compared to a previous Control condition. In the Control condition they foraged at random $(48 \pm 11 \%)$ between two pellet dispensers that delivered food rewards at the same rate, while in the Game condition they increased the preference towards the defection option $(58 \pm 10 \%)$. A sequential (trial by trial) analysis showed that these small birds defected regularly and cooperated at random. While the small preference $(10 \%)$ for defection observed in a weak version of the IPD suggests IPD standard experiments may be exceedingly stringent for research on animal rec-
\end{abstract}


iprocity, the absence of cooperation even in a weak IPD demands further research with our reciprocity experimental design and with other species to shed light on the underlying learning processes.

Keywords: weak Iterated Prisoner's Dilemma; Tit-for-Tat; foraging games; reciprocity; Periparus ater

The prisoner's dilemma (PD) has been used frequently to investigate the evolution of cooperation among selfish individuals. In the PD, individuals engage in pairwise interactions with two behavioral options: they must cooperate (C) or defect (D). Their joint behavior then determines their payoffs. While it is possible to make qualitative predictions about payoffs, quantitative predictions are more difficult (Dugatkin, 1997, 2002). A potential way around this problem is to use operant conditioning methods (Skinner, 1938) with food delivered according to a payoff matrix that satisfies a PD. Mutual cooperation in the most common foraging test pays an amount $\mathrm{R}$ of, for example, 3 food pellets, while mutual defection results in an amount $\mathrm{P}$ of 1 food pellet. If one player defects when the other cooperates, the defector gets an amount $\mathrm{T}$ of, for example, 5 food pellets, and the cooperator is left with the sucker's payoff $S$ of 0 food pellets (e.g. Hall, 2003). Defectors are always better off regardless of their opponent's decision when individuals engage only once in the game. Under the latter condition, the payoff distribution for two players, A and $\mathrm{B}$, in matrix notation is:

$$
\begin{aligned}
& \text { Player B }
\end{aligned}
$$

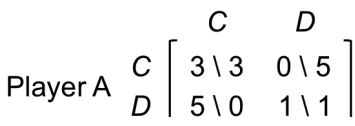

Payoffs of Player B are often concealed because the matrix is diagonally symmetric, and only the payoffs of Player A are shown:

$$
\begin{gathered}
C \\
C \\
D
\end{gathered}\left[\begin{array}{cc}
\mathrm{R}=3 & \mathrm{~S}=0 \\
\mathrm{~T}=5 & \mathrm{P}=1
\end{array}\right]
$$

Consequentially, "rational" individuals attempting to maximize their short-term profits when the game is played only once typically must defect because $\mathrm{T}>\mathrm{R}$ $>\mathrm{P}>\mathrm{S}$. In the repeated or iterated prisoner's dilemma (IPD) there is a second 
constraint on the payoff values: $R>(S+T) / 2$. This latter constraint ensures that mutual cooperation pays the highest food reward to both players when the game is played more than once. The difficulty here is that each player benefits maximally by defecting while the other player cooperates and benefits minimally by cooperating while the other player defects.

There is a large theoretical and empirical literature on game theory and animal behavior in the context of IPD with payoff matrices like the one previously described. Zero food rewards (e.g., the Sucker's payoff $S=0$ ) are usually represented in the matrix notation with a minus sign (-), while positive food rewards are represented with a plus sign $(+)$, whatever the number of rewards delivered. In most IPD experimental studies it is common that matrices like

$$
C\left[\begin{array}{cc}
C & D \\
D=+ & \mathrm{S}=- \\
\mathrm{T}=+ & \mathrm{P}=++
\end{array}\right]
$$

favor mutual defection, and matrices like:

$$
C\left[\begin{array}{cc}
C & D \\
D=+ & \mathrm{S}=- \\
\mathrm{T}=+ & \mathrm{P}=-
\end{array}\right]
$$

favor mutual cooperation (Stephens \& Clements, 1998). These results agree with the fact that losses outweigh gains, because losses of energy have a bigger impact on fitness than equivalent gains. This is so because losses can sometimes lead to death (Houston, Fawcett, Mallpress, \& McNamara, 2014).

These payoff matrices can be troublesome in foraging experiments. For instance, the null reward typically assigned to the sucker's payoff can be a net loss after discounting the costs (time, energy) of awaiting consecutive foraging trials without any food. Moreover, consecutive foraging trials without any food pellet lengthen the perceived intertrial interval (ITI) until the next food reward.. Longer ITIs after trials without any food pellets introduces ITI variability in the IPD and could result in the discouting of food pellet value (e.g. Benson \& Stephens, 1996). Such discounting could severely limit the IPD game as a model of animal cooperation (Stephens, 2000,2002 ). Thus, foraging trials without any food pellet must be avoided in IPD experiments. For instance, the sucker's payoff could be $S=1$ instead of $S=0$. 
The study of IPD in a foraging context may be simplified not only by the removal of foraging trials without any food pellets but also removing the difference between $S$ and $P$, relaxing the typical IPD's payoff matrix. A payoff matrix in which $\mathrm{P}=\mathrm{S}$ is a payoff matrix satisfactory enough for an IPD test in a foraging context, because it retains the inequality $\mathrm{R}>(\mathrm{S}+\mathrm{T}) / 2$ (Nowak \& May, 1992). The payoff matrix can be weakened further reducing the temptation to defect by matching its payoff to $\mathrm{R}$. A weak IPD with $\mathrm{T}=\mathrm{R}>\mathrm{P}=\mathrm{S}$ (Kuhn, 2014) ensures that mutual cooperation pays the highest food reward to both players when the game is played more than once. The weak IPD matrix is

$$
\begin{gathered}
C \\
C \\
D
\end{gathered}\left[\begin{array}{cc}
\mathrm{R}=3 & \mathrm{~S}=1 \\
\mathrm{~T}=3 & \mathrm{P}=1
\end{array}\right]
$$

Such a weak payoff matrix has been tested with blue jays Cyanocitta cristata (Stephens \& Clements, 1998) foraging under laboratory conditions. Blue jays cooperated $36.4 \%$ of the time when they played with a payoff matrix of $\mathrm{T}=\mathrm{R}=5$ food pellets, and $\mathrm{P}=\mathrm{S}=1$ food pellet. Although that frequency was greater than full defection, this result showed that blue jays selected the less reinforcing foraging option more often than the foraging option that provided more food pellets in the long term. More IPD-like games with the same payoff matrix structure as the Stephens and Clements (1998) experiment may provide valuable insights into cooperative behavior, because results from a greater taxonomic range of species may help to understand the ecological and evolutionary limits that shape the evolution of cooperative behavior.

Social cooperation in the IPD also has been explored in nonsocial contexts by replacing the coactor with a computer acting as a virtual player that mirrors the last preference of the animal, resulting in the animal cooperating or defecting with itself (Baker \& Rachlin, 2002b; Hall, 2003; Sanabria, Baker, \& Rachlin, 2003). In the present experiment we tested a weak IPD in a game controlled by a computer program that recorded the preferences of a single animal to explore whether the animal would show direct reciprocity towards itself. Our aim was to investigate whether defection reported in many IPD games also is predominant in IPD-like games when defection-prone factors are relaxed or even fully removed.

A secondary aim was to broaden the taxonomic scope of experimental tests of IPD-like games by using coal tits (Periparus ater), a bird species of small size (c. 
$10 \mathrm{~g}$ ). Coal tits are suitable to study the weak IPD because they have a disproportionately larger hippocampus. The size of the hippocampus, a brain region essential to learning and memory (i.e., recall), is correlated with tasks involving an extra demand for learning and recall (Smulders, Gould, \& Leaver, 2010). The hippocampus has a specific contribution to contextually mediated retrieval, because events that are said to be recorded into episodic memory may trigger episodic learning, i.e. a change in behavior that occurs as a result of an event (Long et al., 2017; Terry, 2009). Moreover, what coal tits learn decays at a slower rate than in other parids (Biegler et al., 2001; Healy \& Krebs, 1996). Thus coal tits might be expected to show enough control over the outcomes of their foraging behavior, maximizing food intake over longer periods than closely related nonstoring species, which means this species would play cooperation in a weak IPD game.

\section{Method}

\section{Subjects}

The subjects were six adult coal tits of unknown sex. The experiment was performed in the year 2000. The same birds were used in a previous experiment (Bautista, Martin, Martinez, \& Mayo, 2001). Each bird was housed in a separate cage measuring $1.0 \times 0.4 \times 0.3 \mathrm{~m}$. Temperature in the laboratory was constant and set at $24{ }^{\circ} \mathrm{C}$ before the experiment started. The light-dark cycle was 9:15 (L:D), with the lights on from 0915 hours to 1815 hours. In the daytime period, the lights were brightened and dimmed gradually. The birds were visually but not acoustically isolated from others. The birds were kept in the experiment and then released to the wild afterwards in accord with ethical guidelines in behavior research (Appendix A).

\section{Apparatus}

The experiment was conducted in each bird's home cage. Each cage had two perches, one at each side of the cage, and two food hoppers (accessible via a $4.0 \times$ $3.5 \mathrm{~cm}$ aperture) on the back wall of the cage (Fig. 1A). Food-storing species of Paridae rely on spatial cues such as the position or location of the feeder (Brodbeck, 1994; Clayton, 1995), hence subjects were tested in cages provided with the two indicated food hoppers. Each food hopper was $10 \mathrm{~cm}$ above the cage floor and the distance between them was $20 \mathrm{~cm}$. Each food hopper contained a light bulb and a pecking door, plus a small perch connected to the computer. Lights signalled which hopper was active and the small perch recorded the bird's preference when the bird 
jumped on it. A pellet dispenser (Campden Instruments, Loughborough, U.K.) delivered food pellets in the selected food hopper when the hopper was active and after the small perch was pressed once. Food pellets were made by grinding and sieving dry kitten cookies (The IAMS Company, Dayton, Ohio, USA) to small, even-sized pieces. One food pellet averaged $0.041 \mathrm{~g}$ and took $1 \mathrm{~s}$ to deliver. An Acorn RiscPC-600 microcomputer running Arachnid experimental control language (Paul Fray Ltd., Cambridge, UK) controlled the stimulus events (lights), response contingencies (food hopper selected and food delivery) and recorded the time delay since the food was offered until the coal tit made its next food request. We called this period of time the latency.

\section{Procedure}

Training. Each bird was trained to jump to the hopper's perch by an autoshaping procedure between 0930 to 1800 hours for two weeks before the experiment started. The coal tits initially experienced the delivery of one unit of food preceded by $10 \mathrm{~s}$ of a light in a food hopper. Then a new unit of food was released using the same procedure in the other food hooper. Gradually units of food were delivered conditional on perching, keeping the light on until the bird landed on the perch. At the end of training, the birds lived in a closed economy (Collier, 1983; Hursh, 1980), obtaining all their food through the experimental schedule of reinforcement. Maximum food delivery could have reached $29.3 \mathrm{~g} /$ day in the training period in this system, twelve times higher than the coal tit's ad libitum daily intake of $2.3 \pm 0.1$ $\mathrm{g} /$ day at $24^{\circ} \mathrm{C}$ air temperature (Bautista, Martin, et al., 2001). Thus, the coal tits did not experience food shortage. The animals were in a free-operant situation, in this case a closed economy in which they have to continuously respond to ensure obtaining sufficient food for survival.

We set the ITI as $20 \mathrm{~min}$, a period long enough to ensure that coal tits maximize food intake rate from dawn to dusk in the experimental setup (Bautista, Martin, et al., 2001). The remarkably small size of coal tits and the large size of food pellets posed a constraint on the ITI, which was long enough to avoid satiation too early in the session. A day segmented in 20 -min periods is not unrealistic because in nonlaboratory settings, foraging interruptions of several minutes from dawn to dusk are common (Carrascal \& Polo, 1999; Polo \& Carrascal, 1997). This long ITI thus could be envisioned as an element of an interrupted foraging routine. A 20-min ITI should not impede cooperation, even though the effect of the ITI in 
coal tits' behavior warrants further exploration (for instance, its effect in long-term maximization, Jones \& Moore, 1999).

Conditions. There were two conditions, a Control and a Game that were defined by the foraging rules applied to the birds. The Control condition was conducted to identify a preference bias to one or other hopper when both delivered the same amount of food, and the Game condition was the IPD game. We used the term "trial" to describe the events required to obtain the food pellets. In the Control condition trials were grouped in blocks of three: two forced trials followed by a free trial. In the Game condition there were only free trials (Fig. 1B). In forced trials one of the hoppers was active until a food pellet was collected, so that animals could not choose the hopper to be accessed. A forced trial started with the illumination of the light bulb above one of the hoppers with a probability of $p=.50$. After the bird perched at the illuminated hopper and the food was delivered, 20 min elapsed (the ITI), and then the light bulb associated with the other hopper was switched on and the food delivered after the bird perched on that hopper. Twenty minutes after the latter trial, a free trial started with the illumination of both hoppers, allowing the bird to choose the hopper. When the bird switched on one of the small perches, the programmed number of food pellets were delivered from the associated hopper, the light of the other hopper was turned off, and the next ITI started. The procedure is shown schematically in Figure 1B. As noted, two forced trials always were followed by a free one in the Control condition. Foraging cycles were of two types, depending on the number of food pellets delivered. In low foraging cycles one food pellet was delivered in each trial, and in high foraging cycles three food pellets were delivered in each trial. Low and high foraging cycles alternated in the Control condition to provide a baseline amount of food during each day. The free trials of the Control condition allowed measurement of bias for one or the other food hopper. Forced trials were not included in the Game condition because the computer was programmed to deliver food pellets according to the 'tit-for-tat' strategy (TFT), thus the number of food pellets delivered in each trial depended on the bird's prior choice.

The Game condition was implemented on completion of the Control condition. The computer delivered food pellets according to the TFT strategy and mirrored the bird's previous choice of food hopper. Before the game started, one of the food hoppers was randomly set as the "defecting" site and the other as the "cooperating" site, keeping this state until the end of the game. One of the food hoppers was labeled as the "defecting" site because the computer provided $\mathrm{T}=3$ food pellets 
A - View of an Experimental Aviary

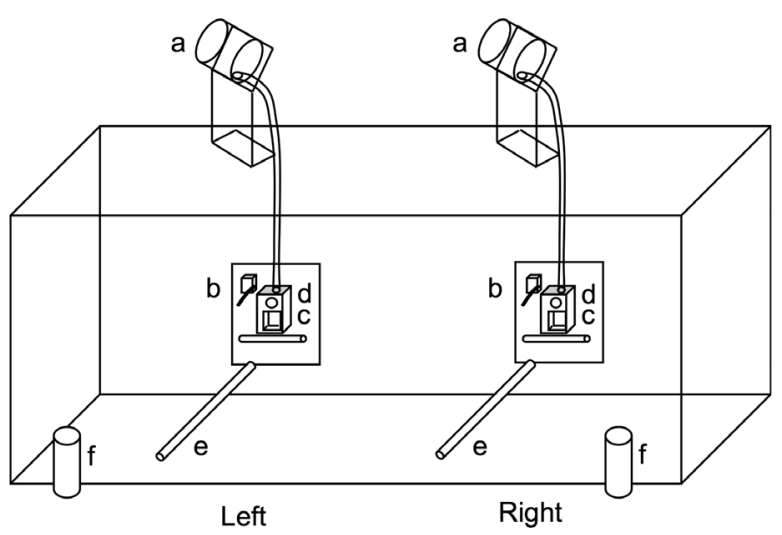

B - Experimental Schedule

Trials in Control Condition

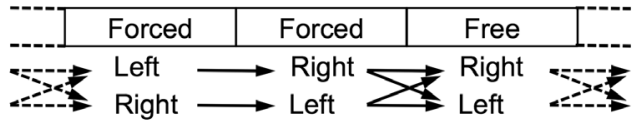

Trials in Game Condition

\begin{tabular}{l|c|c|}
\hline Free & Free & Free \\
\hline Light $\longrightarrow$ Right $\longrightarrow$ Right
\end{tabular}

Figure 1. A. Diagram of the experimental cage drawn to scale. In each cage there were two pellet dispensers (a), two drinking bottles (f) and two perches (e). Each pellet dispenser was connected by a plastic pipe to a food hopper that included a bulb light (d) and a door (c) to avoid food spillage. A small switchable perch (b) was attached to each food hopper to release the food delivery. The cooperative and defecting sites were assigned at random for each bird. B. Schematic overview of the experimental schedule in Control and Game conditions. After the ITI finished, the bulb lights were switched on showing the start of a trial, which ended with a food pellet after the bird jumped on the small switchable perch. The Control condition included a forced trial at each side of the cage followed by a free trial at the side chosen by the bird. The Game condition included free trials only.

when the bird chose it the first time, but $\mathrm{P}=1$ food pellet in subsequent trials and until the bird chose the other food hopper. The other food hopper was labeled the "cooperating" site, because it provided $S=1$ food pellets when it was chosen the first time, but $\mathrm{R}=3$ food pellets in subsequent trials until the bird chose the other food hopper. In this game being selfish (defecting) pays less than being cooperative (cooperating) when the game is played repeatedly. The payoff $\mathrm{T}=3$ was obtained at the defecting site every time the bird changed from the cooperating site to the defecting site, where the payoff became $\mathrm{P}=1$ if the bird repeatedly chose this defecting hopper. The payoff $S=1$ was obtained at the cooperating site the first time the bird changed to it from the defecting site, but thereafter the payoff $\mathrm{R}=3$ replaced the payoff $S=1$ when the player selected the cooperating site. 
Every day we recorded body mass, food intake, a sample of hopping activity for each bird and their latency to perch at the illuminated food hopper. All these measures were implemented to ensure the birds were prone to maximize food intake without suffering unnecessary food deprivation. We weighed the birds to the nearest $0.01 \mathrm{~g}$ at 0915 hours (early morning) and 1800 hours (evening). Every day at 0930 hours we sampled the activity of two birds by counting the number of hops between perches and walks occurring during a 10-min period. We found no significant differences between Game and Control conditions in the activity rate (number of hops/min), response latency (s), body mass at early morning and evening (g) and food intake (g/day). Latency was not recorded separately for cooperation trials and defection trials. These data are provided in Appendix B.

\section{Data analyses}

Sequential (trial by trial) analysis. Cooperation requires attention to individual action based on the prior selection because the payoff matrix links the amount of food to both the present and immediately past decisions. We explored the relation between pairs of sequential trials and calculated the probabilities of food hopper switch in Control and Game conditions.

In the Control condition the same amount of food was delivered in both food hoppers, and therefore the probability of change between response types (cooperation, defection) during a free trial given the response in the previous forced trial $\left(p_{\text {CTRL }}\right)$ must be $p_{\text {CTRL }}=.5$ if the birds select a food hopper by chance. We tested this prediction with all free trials in the Control condition $\left(\mathrm{H}_{0}: p_{\text {CTRL }}=.5\right)$. We also tested it within low foraging cycles $\left(\mathrm{H}_{0}: p_{\text {CTRL low }}=.5\right)$ or high foraging cycles $\left(\mathrm{H}_{0}\right.$ : $p_{\text {CTRL high }}=.5$ ), because in a low foraging cycle both responses types provided 1 food pellet but 3 food pellets in a high foraging cycle.

In the Game condition the probability of no change between food hoppers $\left(p_{\text {GAME }}\right)$ in sequential trials could be different from that probablility in the Control condition because the amount of food delivered depended on the previous payoff, according to the IPD payoff matrix.Eight pairs of consecutive free trials were possible in the Game condition. These eight pairs are determined by the number of food pellets (either 1 or 3 ) and the food dispensers chosen (either Cooperation or Defection) in previous trial $t$ - 1 and current trial $t:$ Coop $_{1}-$ Coop $_{3}$, Coop 1 -Def , $_{3}$

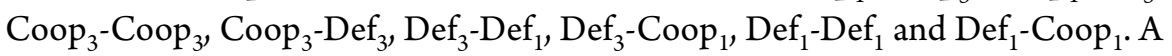
bird randomly feeding between the cooperation and defection food hoppers must show a uniform distribution of sequential pairs of choices, each pair with a proba- 
bility $\mathrm{p}=0.125$ because there are eight possible pairs in the Game condition. Calculations of probabilities are provided in Appendix D.

Each condition lasted seven days and data from the last four days were used in the statistical analyses. In this period 23 to 34 free trials per bird occurred in the Control condition and 104 to 107 free trials per bird occurred in the Game condition (Appendix C: Fig. C1). Statistical differences between conditions were analyzed using ANOVAs with repeated measures in JMP (SAS Institute Inc., 2013). Two factors were defined: condition, a fixed factor with two levels (Control and Game), and subject, a random factor with six levels (Birds A to G). A Spearman rank-order correlation coefficient was calculated to measure the statistical association between frequency of defection, daily food intake, body mass, activity and latency to peck in each condition ( $N=6$ birds). Results are reported as the mean \pm standard error $(\overline{\mathbf{x}} \pm \mathrm{SE})$ and $p$-values were two tailed.

Robust means (Erceg-Hurn \& Mirosevich, 2008) of probabilities $p_{\text {CTRL }}$ and $p_{\text {GAME }}$ across birds were calculated in JMP (SAS Institute Inc., 2013). The Wilcoxon signed-rank test $W$ was calculated to test significant differences relative to a probability of .50 in the Control condition. In the Game condition each bird could nonetheless increase its bias towards one or another food hopper as compared to its preference in the Control condition. We checked this hypothesis calculating the paired Wilcoxon signed-rank test $W$ between matched pairs of $p_{\mathrm{GAME}}$ and $p_{\mathrm{C} \text { - }}$ TRL within birds. The significant probability of repeated feeding at the cooperation or defection food hoppers in the Game condition was tested with the Wilcoxon signed-rank test $W$.

\section{Results}

The percentage of defection choices in the Control condition was near $50 \%$ for four out of the six birds, as shown in Figure 2. The overall percentage of defection choices was $48.7 \pm 11.2 \%$ (mean $\pm \mathrm{SE}, \mathrm{N}=6$ birds). In the Game condition the percentage of defection choices increased to $58.2 \pm 10.2 \%$, significantly greater $(F(1,5)$ $=10.2, p=.023)$ than in the Control condition. The mean $( \pm \mathrm{SE})$ of six individual differences between conditions was $10.2 \pm 3.9 \%$.

Individual mean defection percentage was not correlated with intake, body mass and hopping rate ( $p$-values $>.18$ for all Spearman rank correlation coefficients) in either condition. Correlation coefficients between latency to perch and defection percentage were not significant in either the Control $\left(r_{s}=-.77, p=.085\right)$ or the Game $\left(r_{s}=-.83, p=.064\right)$ condition. 
Figure 2. Preference of six coal tits for the defection food hopper when food was delivered at fixed rate (Control condition) or according to a weak Iterated Prisoner Dilemma (Game condition). Preference is showed as the mean percentage $(\overline{\mathbf{X}} \pm \mathrm{SE})$ of choices for the defection food hopper.

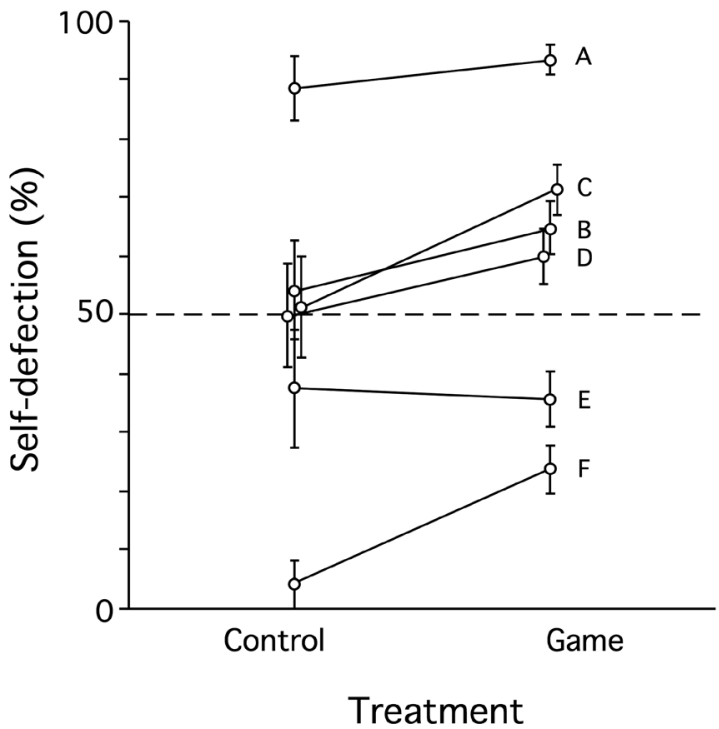

A sequential (trial by trial) analysis in the Control condition yielded a probability of repeating the same option of $p_{\text {CTRL }}=.54 \pm .06$. This probability is not different from chance $(W=3.5, p=.562)$. This same result was obtained in subsets of free trials with one or three food pellets: belonging to low foraging cycles ( 1 food pellet, $\left.p_{\text {CTRL low }}=.59 \pm .06\right)$ and $h i g h$ foraging cycles ( 3 food pellets, $p_{\text {CTRL high }}=.50 \pm .07$ ).

In the Game condition the sequential (trial-by-trial) analysis yielded a mean $p_{\mathrm{GAME}}=.71 \pm .05$. This probability was significantly greater than the .50 expected if change between the food hoppers was random $(W=10.5, p=.031)$ and marginally greater than that observed during the Control condition $(W=8.5, p=.094$, paired test). Mean probabilities of repeated feeding at the cooperation and defection food hoppers did not differ $\left(p_{\mathrm{COOP}}=.50 \pm 13, p_{\mathrm{DEF}}=.70 \pm 10, W=-4.5, p=.437\right.$, paired test). Therefore, the probability of continuing to choose the same food hopper in the Game condition did not depend on the food hopper selected on the previous trial. This absence of a statistical difference, however, could have been masked by the number of food pellets (one or three) delivered in the previous trial. Perhaps the coal tits were prone to stay at the same food hopper (either cooperation or defection) when it delivered three food pellets and to move after 1 food pellet was delivered (a "win-stay, lose-switch" strategy, Nowak \& Sigmund, 1993). Taking into account the number of food pellets delivered from each food hopper in trial $t$ and 


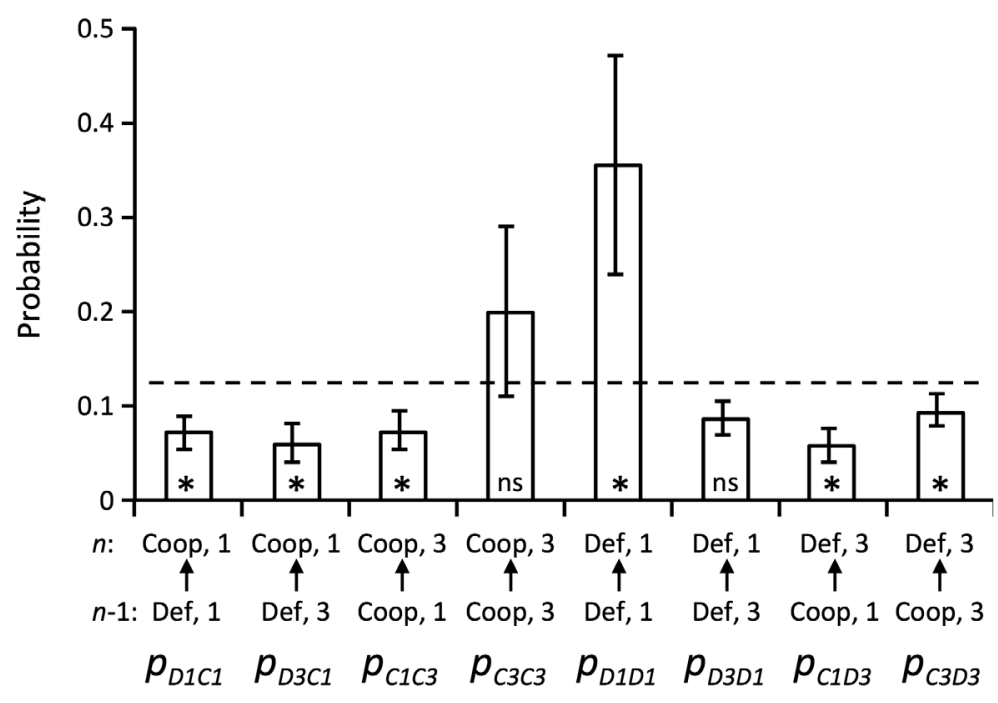

Figure 3. Probabilities $(\overline{\mathbf{X}} \pm \mathrm{SE}$ ) of cooperation (Coop) and defection (Def) in trial $t$, given the response in previous trial $t$-1. Pairs of responses $(t-1, t)$ are showed with the number of food pellets $(1,3)$ delivered according to IPD payoff matrix (e.g. $p$ C1C 3 shows the probability of repeated cooperation with three food pellets, after cooperation a first time with one food pellet). Probabilities greater or smaller than random $(p=.125$, dashed line $)$ are highlighted $\left({ }^{*}: p<.05\right.$, ns: $p>.05$, Wilcoxon signed-rank test, $N=6$ birds).

previous trial $t-1$, the mean probabilities of repeated feeding at the same food hopper after one food pellet $\left(p_{\mathrm{SAME} \mid \mathrm{R}=1}=.76 \pm .04\right)$ or three food pellets $\left(p_{\mathrm{SAME} \mid \mathrm{R}=3}=\right.$ $.63 \pm .04)$ differed statistically ( $W=10.5, p=.031$, paired test). That is, delivering one food pellet, either at the cooperation or the defection food hoppers, increased the probability of staying at the same food hopper more than delivering three food pellets. This counterintuitive result was noteworthy at the defection food hopper (Figure 3, $p_{\mathrm{D} 1 \mathrm{D} 1}=.35 \pm .11$ ).

\section{Discussion}

Most coal tits foraging at two food hoppers showed no systematic preference between the food hoppers in the Control condition when the same amount of food was delivered at a fixed rate from each food hopper, a result that shows the suitability 
of the experimental setup for assesing choice. When food was scheduled according to a weak version of the IPD in the Game condition, a significant shift towards defection was found in coal tits foraging behavior. Sequential (trial-by-trial) analysis showed the coal tits repeatedly selected defection more than other pay-off possibilities, although in our experimental setup we applied a weak IPD matrix to lessen the value of defection. It is difficult to explain how optimal foraging theory (Stephens \& Krebs, 1986) and biological rationality (Kacelnik, 2006), which predict that by foraging most of the times at the cooperation food hopper the coal tits might have maximized their long-term intake rate, can be accommodated to a preference for defection. The lack of maximization of the long-term intake rate might be explained because animals are not perfect optimizers but short-sighted decision makers (Gigerenzer \& Selten, 2002; Stevens, 2013).

Stephens and Clements (1998) found a similar result to the present one with three pairs of blue jays foraging at two food hoppers. The game was played with the same weak payoff matrix structure ( $\mathrm{T}=\mathrm{R}>\mathrm{P}=\mathrm{S}$, Stephens \& Clements, 1998), although the birds played the game in pairs, that is, each bird did not play with itself but with the other bird's preferences. Blue jays defected $64 \%$ of the times the game was played, a similar percentage to the one found in our study (58\%). Although the studies differed in the game structure (playing against another organism vs. playing against a computer reflecting the subject's own choices), the payoff matrix was the same and the result was also equivalent: defection was more likely than cooperation in a weak version of the IPD. A similar result also was found with pigeons playing against a computer that similarly reflected their choices (Baker \& Rachlin, 2002a): although cooperation maximizes reinforcement in the long term, pigeons normally defected. Defection in this latter experiment was attributed by Baker and Rachlin (2002a) to a too-long ITI. Short ITIs (i.e., short delay of reinforcement) are likely to boost cooperation if the prisoner's dilemma against a TFT opponent is analogous to a test of self-control (Baker \& Rachlin, 2002a; Mazur, 1987; Rachlin \& Green, 1972). Long ITIs in IPD games reduced self-control in pigeons (Baker \& Rachlin, 2002a) and blue jays (Stephens, McLinn, \& Stevens, 2002, 2006), and therefore the same could have happened in the experiment with the coal tits. We highlight that the same ITI was set in both experimental conditions, but coal tits foraged randomly in the Control condition as predicted and increased the preference for defection in the Game condition. At the present state of the art of current research of coal tits playing the IPD, we suggest that the results are not compromised by the 20-min ITI, although the ITI is one variable that may warrant further 
exploration if we are to understand how cooperation and self-control interact in coal tits, a species barely studied in IPD games.

There are complementary explanations for the low cooperation of coal tits: food deprivation, and short-term recall to take into account past outcomes in foraging decisions. These explanations are among those that pervade the IPD literature (Dugatkin \& Reeve, 1998; Stephens et al., 2002, 2006; van den Berg \& Weissing, 2015) and we therefore now consider to what extent they might have affected the results. For instance, coal tits might have experienced mild physiological stress in the Game condition due to reduced daily food intake. A fall in blood glucose level due to hunger provokes physiological stress, which itself may have increased impulsivity and suboptimal decisions in other IPD studies (Stephens, 2000; Stephens et al., 2006), but coal tits in the Game condition did not show a significant decrease in the mean latency and the correlation between latency and defection percentage was not significant. We thus conclude that coal tits were not physiologically stressed by a smaller food intake. Another index of physiological stress is low body mass, which changes as a consequence of food deprivation (Bautista \& Alonso, 2013; Bautista, Tinbergen, \& Kacelnik, 2001; Bautista, Tinbergen, Wiersma, \& Kacelnik, 1998). Our birds did not undergo decreased body mass and activity rates (which also suggest there was no energy loss during the Game condition). The present coal tits thus behaved with no such evident physiological stress, eliminating it as an explanation to the increases of proneness to eat at the defection food hopper.

Besides the effects of a smaller food intake, the low cooperation of coal tits may have been an effect of a short-term recall if they cannot take into account past outcomes in foraging decisions. Despite its central importance, the role of recall in cooperation has received little attention in the existing literature (Stevens, Volstorf, Schooler, \& Rieskamp, 2011). Animals should remember some of the previous outcomes of the game or it would be difficult for reciprocity to take place (Taborsky, Frommen, \& Riehl, 2016a). Recall in nonhuman species and their inefficacy to cooperate in an IPD context must be related (Larose \& Dubois, 2011) because such retention duration determines the likelihood of cooperation (e.g. Hauert \& Schuster, 1998; Hauert \& Stenull, 2002). But the coal tit, which, as noted previously, is a food-storing species of Paridae, was selected because it is well suited to solve recall and learning tasks (Marhounova, Frynta, Fuchs, \& Landova, 2017). The size of the hippocampus, a brain region essential to learning and recall, is correlated with tasks involving an extra demand for spatial learning and recall (Smulders, Gould, \& Leaver, 2010). The hippocampus has a specific contribution to contex- 
tually mediated recall, because events that are recorded into episodic recall may trigger episodic learning, i.e., a change in behavior that occurs as a result of an event (Long et al., 2017; Terry, 2009). Parids exhibit recall over about 4 weeks (Brodin \& Kunz, 1997; Hitchcock \& Sherry, 1990; Smulders et al., 2010), and the recall decays in coal tits at a slower rate than in other parids (Biegler et al., 2001; Healy \& Krebs, 1996). Food-storing Paridae species can remember the locations of their caches (Sherry, 1984; Sherry, Krebs, \& Cowie, 1981; Shettleworth \& Krebs, 1986), returning to stored food items that they preferred first and not returning to cache sites from which they had removed the food. This bird species exhibits long-lasting recall (Biegler et al., 2001; Healy \& Krebs, 1996; Male \& Smulders, 2007) well suited for the aims of our study. We selected coal tits to test the IPD because they have a disproportionate big hippocampus and an exceptionally small body mass. We designed the experiment to test whether coal tits could learn a pay-off sequence spread across two food sources. Improved spatial recall could also improve recall duration, compared with non-hoarding species (Rowe \& Healy, 2014). Cooperation and defection food hoppers were separated to aid recall, because animals, and specifically paridae, use spatial landmarks to remember the success of past foraging events (see for instance Barkley \& Jacobs, 1998; Healy \& Krebs, 1992; Hughes \& Blight, 2000; Sherry, 1992). We must remember that the coal tits foraged at random in the Control condition, in accordance to equal food delivering in both food hoppers, but they increased preference for defection in the Game condition. Therefore the spatial design of the experimental set up cannot account for the increase of defection in the Game condition.

Finally, coal tits may have played with a short-sighted strategy by remembering only the last outcome of their decisions. Coal tits could have been prone to stay at the same food hopper (either cooperation or defection) when it delivered three food pellets and to move after it delivered just one food pellet (strategy "win-stay, lose-switch", Nowak \& Sigmund, 1993). However, the probability of repeated feeding at the same food hopper was greater after one food pellet than after three food pellets, and especially in the defection food hopper (Fig. 3). According to these results, we cannot conclude that coal tits behavior was compatible with a "win-stay, lose-switch" strategy and other myopic, short-term strategies such as TFT and related strategies (Allen \& Nowak, 2013; Boerlijst, Nowak, \& Sigmund, 1997; Nowak \& Sigmund, 1992, 1993; Taylor \& Nowak, 2007) that belong to a class labeled "memory-one strategies." This means that the conditional probabilities to cooperate require the recall of only one round. Coal tits increased defection when they were 
confronted with a computer program that delivered food pellets according to the TFT strategy, and there is not a complete explanation for this result.

In summary, the present experiment provides empirical evidence that small birds show a significant preference towards feeding sites that provide less food when birds play IPD and a computer is programmed with a simple TFT strategy. The low cooperation of small birds towards themselves has important consequences if the same controlling variables of defection applied to oneself are also applied to social contexts. Such controlling variables of defection remain unknown in our experiment. There is a possibility that low cooperation reported in other IPD studies (see Taborsky, Frommen, \& Riehl, 2016b, and references therein) also may be observed with a weak payoff matrix $(\mathrm{T}=\mathrm{R}>\mathrm{P}=\mathrm{S}>0$, present study). According to this possibility, a weak IPD could be a promising baseline experimental design for further research developments on reciprocity processes.

\section{References}

Allen, B., \& Nowak, M. A. (2013). Game-Theoretical Models in Biology. Science, 341, 844-844. doi:10.1126/science.1241750

Baker, F., \& Rachlin, H. (2002a). Self-control by pigeons in the prisoner's dilemma. Psychonomic Bulletin \& Review, 9, 482-488. doi:10.3758/bf03196303

Barkley, C. L., \& Jacobs, L. F. (1998). Visual environment and delay affect cache retrieval accuracy in a food-storing rodent. Animal Learning and Behavior, 26, 439-447. doi:10.3758/BF03199237

Bautista, L. M., \& Alonso, J. C. (2013). Factors influencing daily food-intake patterns in birds: a case study with wintering Common Cranes. Condor, 115, 330-339. doi:10.1525/cond.2013.120080

Bautista, L. M., Martin, B., Martinez, L., \& Mayo, C. (2001). Risk-sensitive foraging in coal tits. Behaviour, 138, 69-83. doi:10.1163/156853901750077790

Bautista, L. M., Tinbergen, J., \& Kacelnik, A. (2001). To walk or to fly? How birds choose among foraging modes. Proceedings of the National Academy of Sciences USA, 98, 1089-1094.

Bautista, L. M., Tinbergen, J., Wiersma, P., \& Kacelnik, A. (1998). Optimal foraging and beyond: How starlings cope with changes in food availability. American Naturalist, 152, 543-561.

Benson, K. E., \& Stephens, D. W. (1996). Interruptions, tradeoffs, and temporal discounting. American Zoologist, 34, 506-517. doi:10.1093/icb/36.4.506 
Biegler, R., McGregor, A., Krebs, J. R., Healy, S. D., Yoshida, M., \& Capaldi, R. A. (2001). A larger hippocampus is associated with longer-lasting spatial memory. Proceedings of the National Academy of Sciences USA, 98, 6941-6944. doi:10.1073/pnas.121034798

Boerlijst, M. C., Nowak, M. A., \& Sigmund, K. (1997). The logic of contrition. Journal of Theoretical Biology, 185, 281-293. doi:10.1006/jtbi.1996.0326

Brodbeck, D. R. (1994). Memory for spatial and local cues - a comparison of a storing and a nonstoring species Animal Learning \& Behavior, 22, 119-133. doi:10.3758/bf03199912

Brodin, A., \& Kunz, C. (1997). An experimental study of cache recovery by hoarding willow tits after different retention intervals. Behaviour, 134, 881-890. doi:10.1163/156853997x00205

Carrascal, L. M., \& Polo, V. (1999). Coal tits, Parus ater, lose weight in response to chases by predators. Animal Behaviour, 58, 281-285. doi:10.1006/anbe.1999.1142

Clayton, N. S. (1995). Development of memory and the hippocampus - comparison of food-storing and non-storing birds on a one-trial associative memory task. Journal of Neuroscience, 15, 2796-2807.

Collier, G. H. (1983). Life in a closed economy: the ecology of learning and motivation. In M. D. Zeiler \& P. Harzem (Eds.), Advances in the Analysis of Behavior (Vol. 1, pp. 223-274). Chichester, UK.: John Wiley \& Sons Ltd.

Dugatkin, L. A. (1997). Cooperation among animals: An evolutionary perspective (R. M. May \& P. H. Harvey Eds. 1 ed.). New York \& Oxford: Oxford University Press.

Dugatkin, L. A. (2002). Cooperation in animals: An evolutionary overview. Biology \& Philosophy, 17, 459-476. doi:10.1023/a:1020573415343

Dugatkin, L. A., \& Reeve, H. K. (1998). Game theory and animal behavior. New York: Oxford University Press.

Erceg-Hurn, D. M., \& Mirosevich, V. M. (2008). Modern robust statistical methods: An easy way to maximize the accuracy and power of your research. American Psychologist, 63, 591-601. doi:10.1037/0003-066x.63.7.591

Gigerenzer, G., \& Selten, R. (Eds.). (2002). Bounded rationality: The adaptive toolbox: Massachusetts Institute of Technology Press.

Hall, S. S. (2003). Transitions between cooperative and non-cooperative responding in the 'Pigeon's Dilemma'. Behavioural Processes, 60, 199-208. doi:10.1016/ s0376-6357(02)00123-7 
Hauert, C., \& Schuster, H. G. (1998). Extending the iterated Prisoner's Dilemma without synchrony. Journal of Theoretical Biology, 192, 155-166. doi:10.1006/ jtbi.1997.0590

Hauert, C., \& Stenull, O. (2002). Simple adaptive strategy wins the prisoner's dilemma. Journal of Theoretical Biology, 218, 261-272. doi:10.1006/jtbi.2002.3072

Healy, S. D., \& Krebs, J. R. (1992). Comparing spatial memory in two species of tit: recalling a single positive location. Animal Learning and Behavior, 20, 121-126. doi:10.3758/BF03200409

Healy, S. D., \& Krebs, J. R. (1996). Food storing and the hippocampus in Paridae. Brain Behavior And Evolution, 47, 195-199. doi:10.1159/000113239

Hitchcock, C. L., \& Sherry, D. F. (1990). Long-term-memory for cache sites in the black-capped chickadee. Animal Behaviour, 40, 701-712. doi:10.1016/ s0003-3472(05)80699-2

Houston, A. I., Fawcett, T. W., Mallpress, D. E. W., \& McNamara, J. M. (2014). Clarifying the relationship between prospect theory and risk-sensitive foraging theory. Evolution and Human Behavior, 35, 502-507. doi:10.1016/j. evolhumbehav.2014.06.010

Hughes, R. N., \& Blight, C. M. (2000). Two intertidal fish species use visual association learning to track the status of food patches in a radial maze. Animal Behaviour, 59, 613-621. doi:10.1006/anbe.1999.1351

Hursh, S. R. (1980). Economic concepts for the analysis of behaviour. Journal of Experimental Analysis of Behavior, 34, 219-238. doi:10.1901/jeab.1980.34-219

Jones, J. R., \& Moore, J. (1999). Some effects of intertrial-interval duration on discrete-trial choice. Journal of the Experimental Analysis of Behavior, 71, 375-393. doi:10.1901/jeab.1999.71-375

Kacelnik, A. (2006). Meanings of rationality. In S. Hurley \& M. Nudds (Eds.), Rational Animals? (pp. 87-106). Oxford: Oxford University Press.

Kuhn, S. (2014). Prisoner's dilemma. In E. N. Zalta (Ed.), The Stanford Encyclopedia of Philosophy. In E. N. Zalta (Series Ed.) (Fall 2014 ed.): Stanford University. Retrieved from <http://plato.stanford.edu/archives/fall2014/entries/ prisoner-dilemma/>.

Larose, K., \& Dubois, F. (2011). Constraints on the evolution of reciprocity: an experimental test with zebra finches. Ethology, 117, 115-123. doi:10.1111/j.1439-0310.2010.01850.x

Long, N. M., Sperling, M. R., Worrell, G. A., Davis, K. A., Gross, R. E., Lega, B. C., ... Kahana, M. J. (2017). Contextually Mediated Spontaneous Retrieval Is 
Specific to the Hippocampus. Current Biology, 27, 1074-1079. doi:10.1016/j. cub.2017.02.054

Male, L. H., \& Smulders, T. V. (2007). Memory for food caches: not just for retrieval. Behavioral Ecology, 18, 456-459. doi:10.1093/beheco/arl107

Marhounova, L., Frynta, D., Fuchs, R., \& Landova, E. (2017). Object permanence in the food-storing coal tit (Periparus ater) and the non-storing great tit (Parus major): is the mental representation required? Journal of Comparative Psychology, 131, 115-127. doi:10.1037/com0000061

Mazur, J. (1987). An adjusting procedure for studying delayed reinforcement. In M. Commons, J. Mazur, J. Nevin, \& H. Rachlin (Eds.), Quantitative analysis of behavior, vol 5, The effect of delay and of intervening events on reinforcement value (Vol. 5, pp. 55-72). Hillsdale, New Jersey: Lawrence Erlbaum.

Nowak, M. A., \& May, R. M. (1992). Evolutionary games and spatial chaos. Nature, 359, 826-829. doi:10.1038/359826a0

Nowak, M. A., \& Sigmund, K. (1992). Tit for tat in heterogeneous populations. Nature, 355, 250-253. doi:10.1038/355250a0

Nowak, M. A., \& Sigmund, K. (1993). A strategy of win-stay, lose-shift that outperforms tit-for-tat in the Prisoner's Dilemma game. Nature, 364, 56-58. doi: $10.1038 / 364056 \mathrm{a} 0$

Polo, V., \& Carrascal, L. M. (1997). The winter diurnal cycle of body weight in a wild population of Parus cristatus in Central Spain. Ardeola, 44, 215-224.

Rachlin, H., \& Green, L. (1972). Commitment, choice, and self-control. Journal of the Experimental Analysis of Behavior, 17, 15-22. doi:10.1901/jeab.1972.17-15

Rowe, C., \& Healy, S. D. (2014). Measuring variation in cognition. Behavioral Ecology, 25, 1287-1292. doi:10.1093/beheco/aru090

Sanabria, F., Baker, F., \& Rachlin, H. (2003). Learning by pigeons playing against tit-for-tat in an operant prisoner's dilemma. Learning \& Behavior, 31, 318-331. doi:10.3758/BF03195994

SAS Institute Inc. (2013). JMP (Version 11.1.1). Cary, NC, U.S.A. Retrieved from http://www.jmp.com

Sherry, D. (1984). Food storage by black-capped chickadees - memory for the location and contents of caches. Animal Behaviour, 32, 451-464. doi:10.1016/ s0003-3472(84)80281-x

Sherry, D. F. (1992). Landmarks, the hippocampus, and spatial search in food-storing birds. In W. K. Honig \& J. G. Fetterman (Eds.), Cognitive aspects of stimulus control (pp. 185-201). Hillsdale, England: Lawrence Erlbaum Associates, Inc. 
Sherry, D. F., Krebs, J. R., \& Cowie, R. J. (1981). Memory for the location of stored food in marsh tits. Animal Behaviour, 29, 1260-1266. doi:10.1016/ s0003-3472(81)80078-4

Shettleworth, S. J., \& Krebs, J. R. (1986). Stored and encountered seeds: a comparison of two spatial memory tasks in marsh tits and chickadees. Journal of Experimental Psychology, 12, 248-257. doi:10.1037/0097-7403.12.3.248

Skinner, B. F. (1938). The behavior of organisms. New York: Appleton Centruy Crofts. Smulders, T. V., Gould, K. L., \& Leaver, L. A. (2010). Using ecology to guide the study of cognitive and neural mechanisms of different aspects of spatial memory in food-hoarding animals. Philosophical Transactions of the Royal Society B-Biological Sciences, 365, 883-900. doi:10.1098/rstb.2009.0211

Stephens, D. W. (2000). Cumulative benefit games: achieving cooperation when players discount the future. Journal of Theoretical Biology, 205, 1-16. doi:10.1006/ jtbi.2000.2041

Stephens, D. W. (2002). Discrimination, discounting and impulsivity: a role for an informational constraint. Philosophical Transactions of the Royal Society of London Series B Biological Sciences, 357, 1527-1538. doi:10.1098/rstb.2002.1062

Stephens, D. W., \& Clements, K. C. (1998). Game theory and learning. In L. A. Dugatkin \& H. K. Reeve (Eds.), Game theory and animal behavior (pp. 239-260). Oxford: Oxford University Press.

Stephens, D. W., \& Krebs, J. R. (1986). Foraging Theory. Princeton: Princeton University Press.

Stephens, D. W., McLinn, C. M., \& Stevens, J. R. (2002). Discounting and reciprocity in an iterated prisoner's dilemma. Science, 298, 2216-2218. doi:10.1126/ science.1078498

Stephens, D. W., McLinn, C. M., \& Stevens, J. R. (2006). Effects of temporal clumping and payoff accumulation on impulsiveness and cooperation. Behavioural Processes, 71, 29-40. doi:10.1016/j.beproc.2005.09.003

Stevens, J. R. (2013). The bounds of rationality and cognitive building blocks. Behavioral Ecology, 24, 13-14. doi:10.1093/beheco/ars089

Stevens, J. R., Volstorf, J., Schooler, L. J., \& Rieskamp, J. (2011). Forgetting constrains the emergence of cooperative decision strategies. Frontiers in Psychology, 2, 12. doi:10.3389/fpsyg.2010.00235

Taborsky, M., Frommen, J. G., \& Riehl, C. (2016a). Correlated pay-offs are key to cooperation. Philosophical Transactions of the Royal Society of London Series B Biological Sciences, 371, 16. doi:10.1098/rstb.2015.0084 
Taborsky, M., Frommen, J. G., \& Riehl, C. (2016b). The evolution of cooperation based on direct fitness benefits. Philosophical Transactions of the Royal Society of London Series B Biological Sciences, 371. doi:10.1098/rstb.2015.0472

Taylor, C., \& Nowak, M. A. (2007). Transforming the dilemma. Evolution, 61, 22812292. doi:10.1111/j.1558-5646.2007.00196.x

Terry, W. S. (2009). Learning and memory: Basic principles, processes, and procedures (4th ed.). Boston, US: Psychology Press.

van den Berg, P., \& Weissing, F. J. (2015). The importance of mechanisms for the evolution of cooperation. Proceedings of the Royal Society B-Biological Sciences, 282, 9. doi:10.1098/rspb.2015.1382 


\section{Appendix A}

\section{Compliance with ethical standards}

We chose coal tits for this experiment because they are the least aggressive species of the Paridae (Cramp \& Perrins, 1994). The capture of birds and the experiments were licensed by the Consejería de Medio Ambiente y Desarrollo de la Comunidad de Madrid (Spain) to research project PB95-0102-CO2-01. Although birds were housed in small cages, because of limited space in the laboratory, we did not observe detrimental effects of the rearing conditions on behaviour and body mass.

Birds were released to the wild at the same site of capture (field research station "Ventorrillo", Madrid, Spain) following the procedure described in Polo and Bautista (2006). Birds were kept for 1 month in a large outdoor aviary at El Ventorrillo field station, the same site where they were captured. The aviary was divided into large cages of $10.5 \mathrm{~m}^{3}(1.7 \times 3.0 \times 2.0 \mathrm{~m})$, separated by a thick, green, plastic net, with pine branches and nesting cages, and ad libitum access to food, water and vitamins. Individuals were gently chased in the aviaries and trained to fly away from humans before we released them. The cages were opened and they were allowed to use all cages. Birds were finally released to the wild after this period of acclimation.

\section{References Appendix A}

Cramp, S., \& Perrins, C. (Eds.). (1994). Handbook of the Birds of Europe, the Middle East, and North Africa: The Birds of the Western Palearctic: Crows to Finches (Vol. VIII). Oxford: Oxford University Press.

Polo, V., \& Bautista, L. M. (2006). Daily routines of body mass gain in birds: 2. An experiment with reduced food availability. Animal Behaviour, 72, 517-522. doi:10.1016/j.anbehav.2005.09.025 


\section{Appendix B}

Table B1. Food intake, body mass, hopping rate and latency in each condition. No significant differences between Control and Game conditions. Statistical differences between conditions were calculated with ANOVA of repetated measurements.

\begin{tabular}{|c|c|c|c|c|}
\hline & Control & Game & $F_{1,5}$ & $p$ \\
\hline Intake (g/day) & $2.1 \pm 0.5$ & $1.6 \pm 0.2$ & 3.7 & .112 \\
\hline Body mass (g) at dawn & $8.96 \pm 0.12$ & $8.84 \pm 0.30$ & 0.4 & .577 \\
\hline Body mass $(\mathrm{g})$ at dusk & $10.17 \pm 0.12$ & $9.91 \pm 0.37$ & 0.9 & .383 \\
\hline Hopping rate (hops/min) & $26 \pm 5$ & $34 \pm 6$ & 1.0 & .358 \\
\hline Latency to feed $(\mathrm{s})^{1}$ & $7.3 \pm 1.5$ & $10.0 \pm 2.6$ & 2.3 & .188 \\
\hline
\end{tabular}

1 Latency to feed: delay since the food was offered and until the coal tit made its food request perching at the small switchable perch attached to each food hopper (Fig. 1). 


\section{Appendix C}

Figure C1. Accumulated percentage of free defection responses by six birds in Control and Game conditions (open and closed dots respectively) and in the last four days of each condition (highlighted with colours). Smoothing lines are showed (lambda $=0.054$ ). Notice that forced trials are not showed in the Control condition

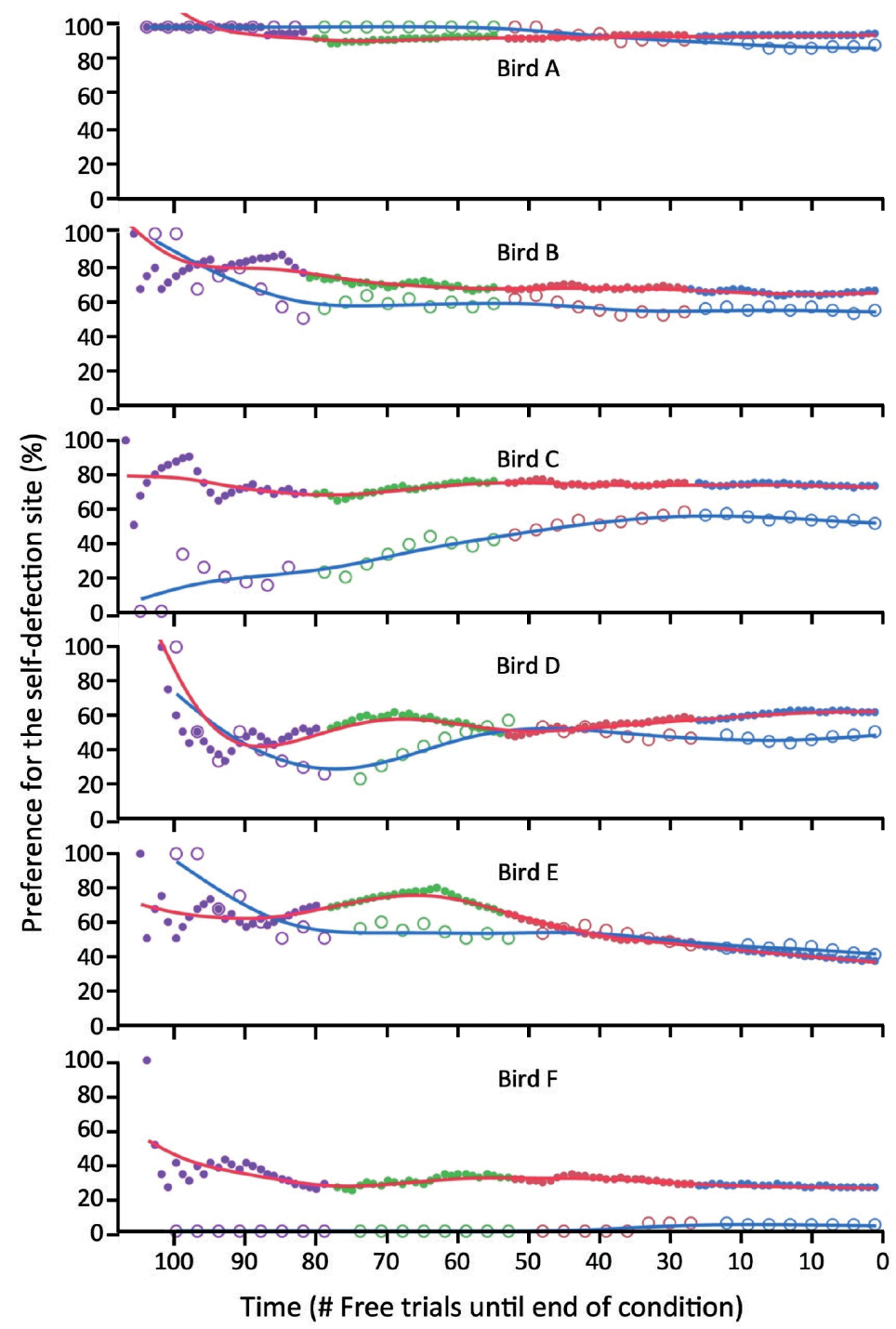




\section{Appendix D}

\section{Probabilities in Sequential analysis (trial by trial)}

Probability of no change between food pellets dispensers in a free trial was calculated in the Control condition as

$$
p_{\text {CTRL }}=\frac{\# \text { free trials with no change of food hopper }}{\# \text { frials with a food hopper change }+ \text { \# free trials with no change of food hopper }}
$$

This probability could be $p_{\mathrm{CTRL}} \neq .5$ because birds show subjective preferences, reluctance or proneness to switch between food hoppers, etc., any of which can bias the expected random preference. The difference could also change according to the foraging cycle (one or three food pellets, respectively low or high cycle). Therefore $p_{\mathrm{CTRL}}$ split into two probabilities $\left(p_{\mathrm{C} 1}\right.$ and $\left.p_{\mathrm{C} 3}\right)$. These three probabilities $\left(p_{\mathrm{CTRL}}\right.$, $p_{\mathrm{C} 1}$ and $\left.p_{\mathrm{C} 3}\right)$ were calculated for each bird.

In the Game condition probabilities of cooperation $\left(p_{\mathrm{COOP}}\right)$ and defection $\left(p_{\mathrm{DEF}}\right)$ were calculated as

$$
p_{i}=\frac{\# \text { trials with no change of food hopper }(i)}{\# \text { trials with a food hopper change }(i)+\# \text { free trials with no change of food hopper }(i)}
$$

where $p_{\mathrm{i}}$ stands for $p_{\mathrm{COOP}}$ or $p_{\mathrm{DEF}}$. Notice that in the Game condition all trials were free. The number of food pellets delivered in trial $t$ and previous trial $t$-1 (either 1 or 3 ) and the food dispenser chosen (either Cooperation or Defection) determine the sequential pairs of trials in the Game condition: Coop ${ }_{1}-$ Coop $_{3}$, Coop $_{1}-$ Def $_{3}$,

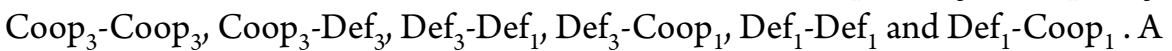
bird feeding at random would show an uniform distribution of pairs at the end of the Game condition, each one with a probability $p=0.125$ because there are eight possible pairs.

In the Game condition probabilities of feeding at the same food hopper after one or three food pellets were delivered ( $p_{\mathrm{SAME} \mid \mathrm{R}=1}$ and $p_{\mathrm{SAME} \mid \mathrm{R}=3}$, respectively) were calculated as

$$
p_{\text {SAME | R }=i}=\frac{\# \text { trials with no change of food hopper }\left(\mid \mathrm{R}_{t-1}=i\right)}{\# \text { trials with a food hopper change }\left(\mid \mathrm{R}_{t-1}=i\right)+\# \text { free trials with no change of food hopper }\left(\mid \mathrm{R}_{t-1}=i\right)}
$$


where $\mid R_{t-1}$ stands for trials preceded by one or three food pellets $\left(p_{\mathrm{SAME} \mid \mathrm{R}=1}\right.$ and $p_{\mathrm{SAME} \mid \mathrm{R}=3}$, respectively).

The number of trials with no change of food hopper after one food pellet was delivered was calculated as

\#trials with no change of food hopper $\left(\mid \mathrm{R}_{t-1}=1\right)=$ \#trials Coop $_{1}-$ Coop $_{3}+$ \#trials $\operatorname{Def}_{1}$-Def ${ }_{1}(4)$

and after three food pellets were delivered was calculated as

\#trials with no change of food hopper $\left(\mid \mathrm{R}_{t-1}=3\right)=$ \#trials Coop $_{3}-\mathrm{Coop}_{3}+$ \#trials $\operatorname{Def}_{3}$-Def 1 (5)

The number of trials with a food hopper change after one food pellet was delivered was calculated as

\#trials with a food hopper change $\left(\mid \mathrm{R}_{t-1}=1\right)=$ \#trials Coop ${ }_{1}-\mathrm{Def}_{3}+$ \#trials $\operatorname{Def}_{1}$-Coop 1 (6)

and after three food pellets it was calculated as

\#trials with a food hopper change $\left(\mid \mathrm{R}_{t-1}=3\right)=$ \#trials Coop ${ }_{3}-\mathrm{Def}_{3}+$ \#trials $\operatorname{Def}_{3}-$ Coop $_{1}(7)$ 